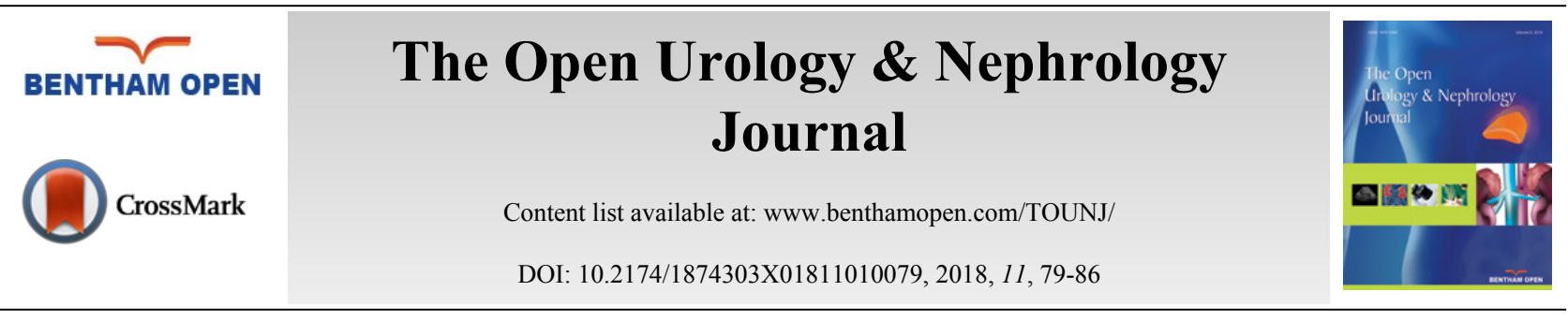

REVIEW ARTICLE

\title{
The Use of Peri-operative Tranexamic Acid and its Potential Applications to Urological Surgery
}

\author{
Jeremy Nettleton ${ }^{1, *}$, Anthony Adimonye ${ }^{1}$, Jonathan Manley ${ }^{2}$, Joseph Jelski', Warren Doherty ${ }^{3}$, \\ Mandy Rees ${ }^{3}$ and Biral Patel ${ }^{1}$ \\ ${ }^{I}$ Department of Urology, Cheltenham General Hospital, Cheltenham, UK \\ ${ }^{2}$ Department of Urology, Pinderfields Hospital, Wakefield, UK \\ ${ }^{3}$ Department of Anaesthesia, Cheltenham General Hospital, Cheltenham, UK
}

Received: July 28, 2018

Revised: October 18, 2018

Accepted: October 22, 2018

\begin{abstract}
Tranexamic acid has been shown to be an effective agent in reducing blood loss in various surgical procedures; however, there is a dearth of evidence for its use and potential side effects in urological surgical procedures. This review discusses the pathophysiology of tranexamic acid, its use in traumatic and surgical bleeding and the current evidence for its potential utilisation in urological surgery.
\end{abstract}

Keywords: Tranexamic acid, Anti-fibrinolytic, Blood loss, Transfusion rate, Urological surgery, Surgical bleeding.

\section{INTRODUCTION}

Tranexamic acid has been shown to reduce the mortality and morbidity of traumatic and surgical bleeding $[1,2]$. It is an established treatment to reduce blood loss and the requirement for transfusion in several elective and emergency surgical procedures [1,3]. Currently, it is being assessed in large multi-national randomised trials in traumatic head injury, and upper gastrointestinal bleeding to re-enforce its evidence base for use in these conditions [4 - 6]. Surgical trials are yet to clearly establish whether there is an increased risk of thromboembolic events.

Tranexamic acid has traditionally been avoided in urology and there is a paucity of urology speciality specific evidence for its effects on transfusion and thrombosis rates. Despite surgical advances some urological surgeries continue to have significant blood loss and transfusion rates. In this review, we discuss the current evidence for tranexamic acid and consider its use in urology surgery.

\section{PATHOPHYSIOLOGY}

There are three anti-fibrinolytics; Epsilon Aminocaproic Acid (EACA), Aprotinin and Tranexamic acid (TA). EACA is a synthetic derivative of lysine and has a strong inhibitory effect on plasminogen. It has been widely used, but large doses are required for it to be effective, as such, a more effective compound was required [7]. Aprotinin is a direct inhibitor of several serine proteases, which include tissue and plasma kallikrein, trypsin and plasmin. By inhibiting plasma kallikrein, aprotinin minimises derangements to coagulation and fibrinolysis [8]. It is an expensive bovine product, and due to the increased risk of mortality, acute renal failure, congestive cardiac failure and stroke [9], it was removed from the market in 2008.

TA, which was discovered by Okamoto et al. [7], is another synthetic derivative of lysine, which is ten times more effective than EACA with a good side effect profile [8]. It reversibly and competitively binds with lysine binding sites

\footnotetext{
* Address correspondence to this author at the Department of Urology, Cheltenham General Hospital, Cheltenham, UK; Tel: 07779 250 534; E-mail: jeremy.nettleton@nhs.net
} 
on plasminogen molecules and consequently reduces the affinity of plasminogen to bind fibrin. Reduced thrombin activity leads to a porous fibrin network, which leads to increased permeability of fibrinogen and impairs fibrinolysis and dissolution of a fibrin clot [10,11]. At increased doses TA may also inhibit plasmin activity [12].

Pharmacodynamically the estimated half-life of TA is about 80 minutes with peak plasma concentrations at 60 minutes. It accumulates in all tissues, freely crosses the placenta, is found in breast milk and is renally excreted [13].

Dosing is highly variable within completed studies using loading doses $2.5 \mathrm{mg} / \mathrm{kg}$ to $100 \mathrm{mg} / \mathrm{kg}$ and maintenance doses of $0.25 \mathrm{mg} / \mathrm{kg} /$ hour to $4 \mathrm{mg} / \mathrm{kg} /$ hour. A meta-analysis evaluating dose response did not show a significant difference in bleeding and transfusions rates between low and high doses [14].

\section{BLEEDING IN TRAUMA AND EMERGENCY PATIENTS}

The Clinical Randomisation of Anti-fibrinolytics in Significant Haemorrhage (CRASH-2) is the largest antifibrinolytics trial and assessed the effects of early administration of TA in trauma patients, with or at risk of significant bleeding. This large multi-national randomised control trial enrolled 20,211 adult patients in over 40 countries. Patients were randomly assigned within 8 hours of injury to either TA monotherapy (utilising a loading dose of $1 \mathrm{~g}$ intravenously over $10 \mathrm{~min}$ then an infusion of $1 \mathrm{~g}$ over 8 hours) or a matched placebo groups [1].

This trial found that all-cause mortality was reduced significantly (14.5\% vs. 16\%; relative risk 0.91 , $95 \% \mathrm{CI}$ $0.85-0.97 ; p=0.0035)$ as was the risk of death related to bleeding $(4.9 \%$ vs. $5.7 \%$ relative risk $0.85 ; 95 \%$ CI $0.76-0.96$ $p=0.0077)$, particularly if treated within 1 hour. However, there was no reduction in rate of transfusion. Both the availability of blood products and transfusion protocols are variable between these forty countries, with only two per cent of trial patients from countries, which routinely provide rapid access to blood products, interventional radiology, trauma surgery and advanced critical care. It has also been hypothesized that some of the death reduction may be secondary to other mechanisms such as anti-inflammatory effects $[1,9]$.

The WOMAN (World Maternal Antifibrinolytic) trial was an international, randomised, double-blind placebocontrolled trial of women aged 16 years and older with a clinical diagnosis of Post-Partum Haemorrhage (PPH) (3). 20000 women whom had a PPH (blood loss of greater than 500mls) were given either $1 \mathrm{~g}$ intravenously of TXA over 10 minutes or placebo. If bleeding continued after 30 minutes or stopped and then re-started within 24 hours of the first dose, a second dose of study drug was administered. There was no difference in the composite end point of all-cause mortality. Mortality was $5.3 \%$ in TXA and $5.5 \%$ in control group. 95\%CI $0.87-1.09 ; \mathrm{p}=0.65$. There was a statistical difference in reduction in deaths from bleeding; 155 (1.5\%) of 10036 vs 191 (1.9\%); Risk Ratio [RR] 0.81, 95\% CI $0 \cdot 65-1 \cdot 00 ; p=0 \cdot 045$. There was an Absolute risk reduction $0.4 \%$; the number needed to treat is 267 . There was no difference in venous thromboembolism, myocardial infarction or sepsis between the groups (3).

The Tranexamic acid for hyperacute primary Intracerebral Haemorrhage (TICH-2): an international randomised, placebo-controlled, phase 3 superiority trial, reported in May, 2018 (4). This international, randomised placebocontrolled trial randomised adults with intracerebral haemorrhage, from acute stroke units, to receive $1 \mathrm{~g}$ intravenous TXA bolus followed by an $8 \mathrm{~h}$ infusion of $1 \mathrm{~g}$ tranexamic acid or a matching placebo, within $8 \mathrm{~h}$ of symptom onset. The primary outcome was functional status at 90 days, post event. 2325 patients were recruited to this trial. The primary outcome did not differ significantly between the groups (adjusted Odds Ratio [aOR] 0·88, 95\% CI 0·76-1 $03, p=0 \cdot 11$ ). There were fewer deaths in the TXA group but this data was not significant (4).

There are a number of ongoing large multicentre multi-national trials evaluating TA in various emergency settings. These include; The Clinical Randomization of an Antibrinolytic in Significant Head injury (CRASH-3) study closes to recruitment on the $31^{\text {st }}$ January 2019, with over 12,000 patients already recruited. The Hemorrhage Alleviation with Tranexamic acid - Intestinal (HALT-IT) trial [5] closes on the $31^{\text {st }}$ May 2019 and has already recruited over 9000 patients.

\section{ANTIFIBRINOLYTICS IN ELECTIVE SURGERY}

A Cochrane review by Henry et al. [14] provides good evidence for the use of TA in elective patients across cardiac, orthopaedic, hepatobiliary, vascular and gynaecological surgery.

Alternatively, the safety of aprotinins was first questioned in 2006 by Mangano et al. [14, 9]. This study assessed different anti-fibrinolytics in 434 patients undergoing revascularization surgery and their respective clinical outcomes. They showed that aprotinins was associated with an increased risk of renal failure, myocardial infarction, heart failure 
and mortality when compared with both TA and EACA. Further analysis, in 2007 by the same group, showed aprotinin as an independent predictor of 5 year mortality [15].

The BART (Blood conservation using Antifibrinolytics in a Randomized Trial) study compared 2331 high risk cardiac surgery patients. It assessed the effects of aprotinin, TA and EACA on 30 day mortality and massive postoperative blood loss. This study was terminated early due to higher mortality in the aprotinin arm, leading to a subsequent withdrawal of the drug from the market [16]. Several reviews have questioned the methodology of this study and a review by the European Medicines Agency also recommended the lifting of the suspension following a review, in limited indications.

With the ongoing safety concerns surrounding aprotinin, this drug has not been and is unlikely to be utilized in the near future in urological surgical procedures. Hence, aprotinin has not been reviewed further especially with the emergence of TA which is cheap, widely employed across specialties and a well-established part of the algorithm for the management of trauma patients.

The systematic review published in 2011 by Henry et al. [14] identified 65 controlled-trials investigating the effect of TA in cardiac $(n=34)$, orthopaedic $(n=27)$, hepatobiliary $(n=2)$, vascular $(n=1)$ and gynaecological $(n=1)$ surgery. In total 2528 patients were randomised to TA therapy and 2314 to a control arm. This review found that TA reduced the need for transfusion by $39 \%$, however specialty-specific analysis only revealed a significant reduction in cardiac, orthopaedic and vascular surgery trials. In addition, it was shown that TA therapy significantly reduced total blood loss, intra-operative and post-operative blood loss, however there was no significant reduction in the re-operation rate for haemorrhage $[2,17]$. Of the trials that reported on mortality and morbidity there was no increased risk in mortality, incidence of myocardial infarction, cerebrovascular events, pulmonary embolism, deep vein thrombosis or renal failure with TA therapy unlike aprotinin $[18,19]$.

Maged et al. [20] showed similar results in their recent trial of preoperative TA in woman undergoing elective cesarean section. This study recruited 100 women to each arm and found blood loss was significantly higher in the placebo group $(700+/-143.9 \mathrm{~mL})$ than in the TA group $(459.4+/-75.41 \mathrm{~mL}, p<0.001)$. There were no reports of thromboembolic events up to four weeks post-operatively.

Kuo [21] et al. completed a meta-analysis assessing the use of Intravenous tranexamic acid revision total joint arthroplasty. 930 patients were included in this study. Intravenous TXA use had a significantly less blood transfusion $(\mathrm{OR}=0.20,95 \% \mathrm{CI}=0.11-0.34, P<0.001)$, lower $\mathrm{Hb}$ drop $(\mathrm{MD}=-0.88,95 \% \mathrm{CI}=-1.31$ to $-0.44, P<0.001)$, and less number of $\mathrm{RBC}$ units transfused $(\mathrm{MD}=-0.44,95 \% \mathrm{CI}=-0.65$ to $-0.24, P<0.001)$ compared to control in the postoperative period. No significant difference was seen in blood loss $(\mathrm{MD}=-245,95 \% \mathrm{CI}=-556$ to $66, P=0.12)$ and VTE events $(\mathrm{OR}=0.57,95 \% \mathrm{CI}=0.13-2.42, P=0.45)$ between groups.

Hodda et al. [22] randomized 60 patients whom were undergoing elective surgery for meningioma to either receive $20 \mathrm{mg} / \mathrm{kg}$ over $20 \mathrm{mins}$ and an infusion of $1 \mathrm{mg} / \mathrm{kg} / \mathrm{hr}$ till conclusion of surgery, or placebo. There was a significant reduction in blood loss of $830 \mathrm{mls}$ vs $124 \mathrm{mls} p=0.03$. There was also a reduced transfusion rate but this was not significant.

Few studies have assessed the potential merits of employing antifibrinolytics in elective urological surgery. Rannikko A et al. [23] and Kumsar S et al. [24], both assessed the role of TA in reducing the amount of blood loss experienced during transurethral resection of the prostate (TURP) in 136 and 40 men, respectively. Rannikko A et al. [23] found that administering $2 \mathrm{~g}$ TA three times on the day of the operation and one day post-op, significantly reduced the operative blood loss associated with TURP $(128 \mathrm{~mL}$ vs. $250 \mathrm{~mL}, p=0.018)$ even with similar amount of tissue resection between the two groups. In addition, they found the use of TA reduced the volume of irrigation fluid required (15 L vs. $18 \mathrm{~L}, p=0.004$ ) and operating time (36 $\min v s .48 \mathrm{~min}, p=0.001)$. Similarly, Kumsar S et al. [24] found intraoperative use of TA reduced operative time $(p<0.001)$, the volume of irrigation fluid needed $(p=0.027)$ and the amount of haemoglobin loss per gram of resected tissue $(p<0.001)$.

Crescenti et al. [25] found in 200 patients undergoing radical retropubic prostatectomy, those treated with intraoperative TA had significantly lower mean intra-operative blood loss $(1103 \mathrm{~mL} v s .1335 \mathrm{~mL}, p=0.02)$ and transfusion rates (absolute risk reduction of 21\%) compared to the placebo group with no significant difference between the incidence of thromboembolic events in the two groups. Similarly, Zaib et al. [26] found in 103 patients who received a TA infusion during open radical cystectomy for bladder cancer that the post-operative blood transfusion rate was significant decreased in comparison to matched controls $(31.1 \%$ vs. $57.7 \%, p<0.0001)$ and TA did not significantly 
increase the pre-operative venous thromboembolic rate $(p=0.52)$.

\section{THROMBOEMBOLISM, CONTRAINDICATION AND SIDE EFFECTS}

Concerns regarding a theoretical increased risk of thromboembolic disease with the use of TA have in part been responsible for its cautious and perhaps decreased use.

However, large systematic reviews have shown no increase in the incidence of thromboembolic events in elective surgery [2, 15]. Likewise, the CRASH-2 trial showed no significant increase in thromboembolic events in trauma patients with TA therapy, and beneficially demonstrated a reduced rate of myocardial infarction [1].

Other side effects of TA previously described include seizures, gastro-intestinal upset and problematic clot formation in macroscopic haematuria. Seizures have been described following administration of high dose TA [19, 27]. GABA is the main inhibitory neurotransmitter in the adult brain. TA inhibits glycine receptors and binds competitively to GABA type A receptors. The lower TA doses used in the CRASH-2 appear safe, however, there is a theoretical lower seizure threshold. Some anaesthetic agents have glycine agonist properties and may help to prevent seizures following surgery $[11,28]$. Nausea and diarrhoea were observed in up to $12 \%$ of patients with $4 \mathrm{~g}$ of TA daily for menorrhagia $[18,29]$.

Macroscopic haematuria has long been regarded as a relative contra-indication for the use of TA due to problems with clot formation. However, there are a number of case reports suggesting improved outcomes in patients with lifethreatening haematuria secondary to polycystic kidney disease with TA therapy [18].

\section{BLOOD LOSS AND TRANSFUSION REQUIREMENTS IN UROLOGICAL SURGERY}

Urological surgery has embraced new techniques and technology to make a substantial shift towards minimally invasive surgery. This shift is widely accepted to have resulted in decreased morbidity and a reduction in the length of stay of many common procedures. Despite this certain common procedures continue to have significant blood loss and transfusion rates, as demonstrated in Table $\mathbf{1}$.

Table 1. Blood Loss and Transfusion Rates Associated with Common Urological Procedures.

\begin{tabular}{|c|c|c|c|}
\hline Procedure & Modality & Median Blood Loss (mL) & Peri-Operative Transfusion Rate (\%) \\
\hline Radical Cystectomy & Open & $350-408[30-33]$ & $2-40[31,33]$ \\
\hline & Laparoscopic & $300-520[34,35]$ & $0-30[34,35]$ \\
\hline & Robotic & $475-800[30,31,33,36]$ & $24-67[31,33,37,38]$ \\
\hline Radical Prostatectomy & Open & $100-191[39,40]$ & $0.5-1.8[40,41]$ \\
\hline & Robotic & $450-745[39-41]$ & $2.9-16.5[39-41]$ \\
\hline Nephrectomy & Open Partial & $131-206[42,43]$ & $4[43]$ \\
\hline & Laparoscopic Partial & $150-300[43,44]$ & $3.8-8.6[40,41,45]$ \\
\hline & Robotic Partial & $367[37]$ & $5.1-12.7[31,37]$ \\
\hline & Open Radical & $262-451[45-47]$ & $28-41[48,50]$ \\
\hline & Laparoscopic Radical & $100-242[33,50,51]$ & $9.2-23[48,50]$ \\
\hline
\end{tabular}

When considering peri-operative haemorrhage and transfusion there are firstly clinical complications but also the impact on wider health. The complications of blood transfusion are well documented and include; haemolytic reactions, transmission of infection, clotting abnormalities, hyperkalaemia, circulatory overload and transfusion related lung injury. In addition, recent studies have also suggested that peri-operative blood transfusion may also decrease survival and result in worse oncological outcomes [27, 28].

In order to reduce the need for transfusion new guidelines and technologies have been implemented. For example, recent National Institute for Health and Care Excellence guidelines suggest the consideration of erythropoietin, intravenous or oral iron, cell salvage and tranexamic acid in patients undergoing surgery to reduce the need for transfusion [29]. Currently, new topical agents such as gelatins, thrombin and fibrin sealants, synthetic glues and collagens have been commonly used intra-operatively to reduce bleeding and the potential need for transfusion.

Haemorrhage and transfusion impacts the wider health service by increasing post-operative length of stay, also with a blood donor service under considerable pressure to continue to recruit enough donors, the benefits of reducing transfusion rates are clear. There may also additional benefits in reducing the risk of haemorrhage in certain cohorts such as Jehovah's witnesses. 
As previously mentioned traditionally TA has been widely avoided by urologists due to the risk of intravesical clot formation in those with haematuria. However, in patients under close observation in the peri-operative period on specialist wards with catheters in-situ the risk of clot retention with TA is hypothesised to be small. In addition, multiple studies that have utilised TA in urological procedures have not shown a significant increase in thromboembolic events with its use $[25,26]$.

\section{RESULTS AND DISCUSSION}

There appears to be good evidence that TA can reduce blood loss and the transfusion rate in a number of emergency and elective settings without a significant elevation in thromboembolic disease and an overall good side effect profile. On-going trials in a variety of settings will help our understanding of the potential benefits or complications of this therapy.

However, the studies assessing elective surgery are predominantly completed in patients who do not have an oncological diagnosis. Urological patients, particularly those undergoing surgery with a higher transfusion rate often have multiple risk factors for thrombo-embolism (pelvic surgery, oncological diagnosis, immobility) and thus care should be taken when considering the potential thromboembolic risk of TA. Though few, the studies assessing the employment of TA in urological procedures highlight its merit in reducing intraoperative blood loss with no significant increase in thromboembolic events.

\section{CONCLUSION}

Tranexamic acid is used widely in emergency and elective surgery and is safe in these settings. Further speciality specific evidence is required to improve the evidence base within urology.

\section{CONSENT FOR PUBLICATION}

Not applicable.

\section{CONFLICT OF INTEREST}

The author declares no conflict of interest, financial or otherwise.

\section{ACKNOWLEDGEMENTS}

Not applicable.

\section{REFERENCES}

[1] Shakur H, Roberts I, Bautista R, et al. Effects of tranexamic acid on death, vascular occlusive events, and blood transfusion in trauma patients with significant haemorrhage (CRASH-2): A randomised, placebo-controlled trial. Lancet 2010; 376(9734): 23-32. [http://dx.doi.org/10.1016/S0140-6736(10)60835-5] [PMID: 20554319]

[2] Ker K, Edwards P, Perel P, Shakur H, Roberts I. Effect of tranexamic acid on surgical bleeding: Systematic review and cumulative metaanalysis. BMJ 2012; 344: e3054.

[http://dx.doi.org/10.1136/bmj.e3054] [PMID: 22611164]

[3] Effect of early tranexamic acid administration on mortality, hysterectomy, and other morbidities in women with post-partum haemorrhage (WOMAN): An international, randomised, double-blind, placebo-controlled trial. Lancet 2017; 389(10084): $2105-16$. [http://dx.doi.org/10.1016/S0140-6736(17)30638-4] [PMID: 28456509]

[4] Sprigg N, Flaherty K, Appleton J, et al. TICH-2 Investigators Tranexamic acid for hyperacute primary IntraCerebral Haemorrhage (TICH-2): an international randomised, placebo-controlled, phase 3 superiority trial 2018. Available from: www.thelancet.com

[5] Roberts I, Coats T, Edwards P, Gilmore I, Jairath V, Ker K, et al. HALT-IT-tranexamic acid for the treatment of gastrointestinal bleeding: study protocol for a randomised controlled trial. Trials 2014; 15

[6] Dewan Y, Komolafe EO, Mejía-Mantilla JH, Perel P, Roberts I, Shakur H. CRASH-3 - Tranexamic acid for the treatment of significant traumatic brain injury: Study protocol for an international randomized, double-blind, placebo-controlled trial. Trials $2012 ; 13$ : 87. [http://dx.doi.org/10.1186/1745-6215-13-87] [PMID: 22721545]

[7] Okamoto S, Sato S, Takada Y, Okamoto U. An active stereo-isomer (trans-form) of amcha and its antifibrinolytic (antiplasminic) action in vitro and in vivo. Keio J Med 1964; 13: 177-85. [http://dx.doi.org/10.2302/kjm.13.177] [PMID: 14279228]

[8] Smith CR. Management of bleeding complications in redo cardiac operations. Ann Thorac Surg 1998; 65(4)(Suppl.): S2-8. [http://dx.doi.org/10.1016/S0003-4975(98)00070-8] [PMID: 9563396] 
[9] Mangano DT, Tudor IC, Dietzel C. The risk associated with aprotinin in cardiac surgery. N Engl J Med 2006; 354(4): 353-65. [http://dx.doi.org/10.1056/NEJMoa051379] [PMID: 16436767]

[10] Blombäck B, Okada M. Fibrin gel structure and clotting time. Thromb Res 1982; 25(1-2): 51-70. [http://dx.doi.org/10.1016/0049-3848(82)90214-6] [PMID: 6121390]

[11] Astedt B. Clinical pharmacology of tranexamic acid. Scand J Gastroenterol Suppl 1987; 137: 22-5. [http://dx.doi.org/10.3109/00365528709089756] [PMID: 3321402]

[12] Hunt BJ. The current place of tranexamic acid in the management of bleeding. Anaesthesia 2015; 70(1)(Suppl. 1): 50-53, e18. [http://dx.doi.org/10.1111/anae.12910] [PMID: 25440395]

[13] Andersson L, Nilsoon IM, Colleen S, Granstrand B, Melander B. Role of urokinase and tissue activator in sustaining bleeding and the management thereof with EACA and AMCA. Ann N Y Acad Sci 1968; 146(2): 642-58. [http://dx.doi.org/10.1111/j.1749-6632.1968.tb20322.x] [PMID: 5254275]

[14] Henry DA, Carless PA, Moxey AJ, et al. Anti-fibrinolytic use for minimising perioperative allogeneic blood transfusion. Cochrane Database Syst Rev 2011; (3): CD001886. [PMID: 21412876]

[15] Mangano DT, Miao Y, Vuylsteke A, et al. Mortality associated with aprotinin during 5 years following coronary artery bypass graft surgery. JAMA 2007; 297(5): 471-9. [http://dx.doi.org/10.1001/jama.297.5.471] [PMID: 17284697]

[16] Fergusson DA, Hébert PC, Mazer CD, et al. A comparison of aprotinin and lysine analogues in high-risk cardiac surgery. N Engl J Med 2008; 358(22): 2319-31. [http://dx.doi.org/10.1056/NEJMoa0802395] [PMID: 18480196]

[17] Vujkovac B, Sabovic M. A successful treatment of life-threatening bleeding from polycystic kidneys with antifibrinolytic agent tranexamic acid. Blood Coagul Fibrinolysis 2006; 17(7): 589-91. [http://dx.doi.org/10.1097/01.mbc.0000245293.41774.c8] [PMID: 16988557]

[18] Preston JT, Cameron IT, Adams EJ, Smith SK. Comparative study of tranexamic acid and norethisterone in the treatment of ovulatory menorrhagia. Br J Obstet Gynaecol 1995; 102(5): 401-6. [http://dx.doi.org/10.1111/j.1471-0528.1995.tb11293.x] [PMID: 7612535]

[19] Murkin JM, Falter F, Granton J, Young B, Burt C, Chu M. High-dose tranexamic Acid is associated with nonischemic clinical seizures in cardiac surgical patients. Anesth Analg 2010; 110(2): 350-3. [http://dx.doi.org/10.1213/ANE.0b013e3181c92b23] [PMID: 19996135]

[20] Maged AM, Helal OM, Elsherbini MM, et al. A randomized placebo-controlled trial of preoperative tranexamic acid among women undergoing elective cesarean delivery. Int J Gynaecol Obstet 2015; 131(3): 265-8. [http://dx.doi.org/10.1016/j.ijgo.2015.05.027] [PMID: 26341174]

[21] Kuo F-C, Lin P-Y, Wang J-W, Lin P-C, Lee MS, Chen AF. Intravenous tranexamic acid use in revision total joint arthroplasty: A metaanalysis. Drug Des Devel Ther 2018; 12: 3163-70. [http://dx.doi.org/10.2147/DDDT.S175407] [PMID: 30288021]

[22] Hooda B, Chouhan RS, Rath GP, Bithal PK, Suri A, Lamsal R. Effect of tranexamic acid on intraoperative blood loss and transfusion requirements in patients undergoing excision of intracranial meningioma. J Clin Neurosci 2017; 41: 132-8. [http://dx.doi.org/10.1016/j.jocn.2017.02.053] [PMID: 28283245]

[23] Rannikko A, Pétas A, Taari K. Tranexamic acid in control of primary hemorrhage during transurethral prostatectomy. Urology 2004; 64(5): 955-8.

[http://dx.doi.org/10.1016/j.urology.2004.07.008] [PMID: 15533485]

[24] Kumsar S, Dirim A, Toksöz S, Sağlam HS, Adsan O. Tranexamic acid decreases blood loss during transurethral resection of the prostate (TUR -P). Cent European J Urol 2011; 64(3): 156-8. [http://dx.doi.org/10.5173/ceju.2011.03.art13] [PMID: 24578884]

[25] Crescenti A, Borghi G, Bignami E, et al. Intraoperative use of tranexamic acid to reduce transfusion rate in patients undergoing radical retropubic prostatectomy: double blind, randomised, placebo controlled trial. BMJ 2011; 343: d5701. [http://dx.doi.org/10.1136/bmj.d5701] [PMID: 22012809]

[26] Zaid HB, Yang DY, Tollefson MK, et al. Efficacy and safety of intraoperative tranexamic acid infusion for reducing blood transfusion during open radical cystectomy. Urology 2016; 92: 57-62. [http://dx.doi.org/10.1016/j.urology.2016.02.044] [PMID: 26968489]

[27] Linder BJ, Thompson RH, Leibovich BC, et al. The impact of perioperative blood transfusion on survival after nephrectomy for nonmetastatic renal cell carcinoma (RCC). BJU Int 2014; 114(3): 368-74. [PMID: 24471825]

[28] Kluth LA, Xylinas E, Rieken M, et al. Impact of peri-operative blood transfusion on the outcomes of patients undergoing radical cystectomy for urothelial carcinoma of the bladder. BJU Int 2014; 113(3): 393-8. [http://dx.doi.org/10.1111/bju.12439] [PMID: 24053618] 
[29] Blood Transfusion National Institute for Health and Care Excellence (NICE) 2015. Available from: https://www.nice.org.uk/guidance/ng24

[30] Wang GJ, Barocas DA, Raman JD, Scherr DS. Robotic vs open radical cystectomy: Prospective comparison of perioperative outcomes and pathological measures of early oncological efficacy. BJU Int 2008; 101(1): 89-93. [PMID: 17888044]

[31] Styn NR, Montgomery JS, Wood DP, et al. Matched comparison of robotic-assisted and open radical cystectomy. Urology 2012; 79(6): 1303-8

[http://dx.doi.org/10.1016/j.urology.2012.01.055] [PMID: 22516354]

[32] Hayn MH, Hussain A, Mansour AM, et al. The learning curve of robot-assisted radical cystectomy: results from the International Robotic Cystectomy Consortium. Eur Urol 2010; 58(2): 197-202. [http://dx.doi.org/10.1016/j.eururo.2010.04.024] [PMID: 20434830]

[33] Parekh DJ, Messer J, Fitzgerald J, Ercole B, Svatek R. Perioperative outcomes and oncologic efficacy from a pilot prospective randomized clinical trial of open versus robotic assisted radical cystectomy. J Urol 2013; 189(2): 474-9. [http://dx.doi.org/10.1016/j.juro.2012.09.077] [PMID: 23017529]

[34] Challacombe BJ, Rose K, Dasgupta P. Laparoscopic radical and partial cystectomy. J Minim Access Surg 2005; 1(4): 188-95. [PMID: 21206662]

[35] Porpiglia F, Renard J, Billia M, et al. Open versus laparoscopy-assisted radical cystectomy: Results of a prospective study. J Endourol 2007; 21(3): 325-9.

[http://dx.doi.org/10.1089/end.2006.0224] [PMID: 17444780]

[36] Chang SS, Smith JA Jr, Wells N, Peterson M, Kovach B, Cookson MS. Estimated blood loss and transfusion requirements of radical cystectomy. J Urol 2001; 166(6): 2151-4. [http://dx.doi.org/10.1016/S0022-5347(05)65524-3] [PMID: 11696725]

[37] Abel EJ, Linder BJ, Bauman TM, et al. Perioperative blood transfusion and radical cystectomy: does timing of transfusion affect bladder cancer mortality? Eur Urol 2014; 66(6): 1139-47. [http://dx.doi.org/10.1016/j.eururo.2014.08.051] [PMID: 25194909]

[38] Lowrance WT, Rumohr JA, Chang SS, Clark PE, Smith JA Jr, Cookson MS. Contemporary open radical cystectomy: Analysis of perioperative outcomes. J Urol 2008; 179(4): 1313-8. [http://dx.doi.org/10.1016/j.juro.2007.11.084] [PMID: 18289578]

[39] Kordan Y, Barocas DA, Altamar HO, et al. Comparison of transfusion requirements between open and robotic-assisted laparoscopic radical prostatectomy. BJU Int 2010; 106(7): 1036-40. [http://dx.doi.org/10.1111/j.1464-410X.2010.09233.x] [PMID: 20151960]

[40] Tewari A, Sooriakumaran P, Bloch DA, Seshadri-Kreaden U, Hebert AE, Wiklund P. Positive surgical margin and perioperative complication rates of primary surgical treatments for prostate cancer: A systematic review and meta-analysis comparing retropubic, laparoscopic, and robotic prostatectomy. Eur Urol 2012; 62(1): 1-15. [http://dx.doi.org/10.1016/j.eururo.2012.02.029] [PMID: 22405509]

[41] Farnham SB, Webster TM, Herrell SD, Smith JA Jr. Intraoperative blood loss and transfusion requirements for robotic-assisted radical prostatectomy versus radical retropubic prostatectomy. Urology 2006; 67(2): 360-3. [http://dx.doi.org/10.1016/j.urology.2005.08.029] [PMID: 16461085]

[42] Benway BM, Bhayani SB, Rogers CG, et al. Robot-assisted partial nephrectomy: An international experience. Eur Urol 2010; 57(5): 815-20. [http://dx.doi.org/10.1016/j.eururo.2010.01.011] [PMID: 20116163]

[43] Spana G, Haber GP, Dulabon LM, et al. Complications after robotic partial nephrectomy at centers of excellence: multi-institutional analysis of 450 cases. J Urol 2011; 186(2): 417-21. [http://dx.doi.org/10.1016/j.juro.2011.03.127] [PMID: 21679980]

[44] Gill IS, Kavoussi LR, Lane BR, et al. Comparison of 1,800 laparoscopic and open partial nephrectomies for single renal tumors. J Urol 2007; 178(1): 41-6. [http://dx.doi.org/10.1016/j.juro.2007.03.038] [PMID: 17574056]

[45] Simmons MN, Gill IS. Decreased complications of contemporary laparoscopic partial nephrectomy: Use of a standardized reporting system. J Urol 2007; 177(6): 2067-73. [http://dx.doi.org/10.1016/j.juro.2007.01.129] [PMID: 17509287]

[46] Sun M, Abdollah F, Shariat SF, et al. Propensity-score matched comparison of complications, blood transfusions, length of stay, and inhospital mortality between open and laparoscopic partial nephrectomy: a national series. Eur J Surg Oncol 2012; 38(1): 80-7. [http://dx.doi.org/10.1016/j.ejso.2011.09.035] [PMID: 21996370]

[47] Abbou CC, Cicco A, Gasman D, et al. Retroperitoneal laparoscopic versus open radical nephrectomy. J Urol 1999; 161(6): 1776-80. [http://dx.doi.org/10.1016/S0022-5347(05)68797-6] [PMID: 10332433]

[48] Nakada SY, Fadden P, Jarrard DF, Moon TD. Hand-assisted laparoscopic radical nephrectomy: Comparison to open radical nephrectomy. Urology 2001; 58(4): 517-20.

[http://dx.doi.org/10.1016/S0090-4295(01)01321-8] [PMID: 11597529] 
[49] Dunn MD, Portis AJ, Shalhav AL, et al. Laparoscopic versus open radical nephrectomy: A 9-year experience. J Urol 2000; $164(4)$ : 1153-9. [http://dx.doi.org/10.1016/S0022-5347(05)67131-5] [PMID: 10992356]

[50] Vricella GJ, Finelli A, Alibhai SM, Ponsky LE, Abouassaly R. The true risk of blood transfusion after nephrectomy for renal masses: A population-based study. BJU Int 2013; 111(8): 1294-300.

[http://dx.doi.org/10.1111/j.1464-410X.2012.11721.x] [PMID: 23368715]

[51] Gill IS, Meraney AM, Schweizer DK, et al. Laparoscopic radical nephrectomy in 100 patients: A single center experience from the United States. Cancer 2001; 92(7): 1843-55

[http://dx.doi.org/10.1002/1097-0142(20011001)92:7<1843::AID-CNCR1701>3.0.CO;2-W] [PMID: 11745257]

\section{(C) 2018 Nettleton et al.}

This is an open access article distributed under the terms of the Creative Commons Attribution 4.0 International Public License (CC-BY 4.0), a copy of which is available at: https://creativecommons.org/licenses/by/4.0/legalcode. This license permits unrestricted use, distribution, and reproduction in any medium, provided the original author and source are credited. 